\title{
Insights from a Global Engineering Outreach Course
}

\author{
Randy S. Lewis \\ Professor, Chemical Engineering Department \\ Brigham Young University \\ Provo, UT 84602 \\ randy.lewis@byu.edu
}

\begin{abstract}
A two-semester multi-disciplinary Global Engineering Outreach (GEO) course was initiated in 2007 to provide an opportunity for junior and senior-level engineering and technology students to design and implement humanitarian-based engineering projects in developing communities. Recently, the course was integrated with a sociology course to enhance the educational opportunities between social scientists and engineers. During the GEO course, students work on small-scale projects that are selected in conjunction with members of the developing communities. Students regularly interact with community members during project development. Following the GEO course, students participate in a two-week implementation trip. Learning outcomes associated with the course are described and assessment results show that many aspects of the learning outcomes are being met but there is room for improvement. In addition, following years of experience, several insights have been identified to help improve the course, community engagement, and implementation trip. Finally, several key aspects that are noteworthy for involving students in designing and implementing projects in developing communities are described.
\end{abstract}

Index Terms: Product design, developing communities, learning outcomes, social science

\section{INTRODUCTION}

Since 2007, a two-semester multi-disciplinary Global Engineering Outreach (GEO) course in the Ira A. Fulton College of Engineering and Technology at Brigham Young University (BYU) has enabled junior and senior-level engineering and technology students to design and implement humanitarian-based engineering projects in developing communities. In 2012, the course was integrated with the Applied Social Research Methods (ASRM) course administered through the Sociology Department to enhance the educational opportunities between social scientists and engineers. This is consistent with a growing movement to integrate social science theory with engineering to strengthen student learning and improving project sustainability ${ }^{1}$.

During the GEO course, students work on small-scale projects that are selected in conjunction with members of the developing communities. Students regularly interact with community members on a near weekly basis via phone calls and email to coordinate and discuss project concepts. Following the GEO course, students participate in a two-week implementation trip. Projects have been implemented in Tonga, Ghana, and Peru with a recent emphasis on Peru. Previous publications related to the course have discussed training internationally responsible engineers ${ }^{2}$, student learning ${ }^{3}$, project sustainability and impact ${ }^{4}$, social constraints ${ }^{5}$, and integration of engineering and social science ${ }^{6}$. 


\section{BACKGROUND}

In 2007, there was a strong student interest to implement a project-based course that would provide an opportunity for students to design and implement projects for developing communities. The initial GEO course began as a variable-credit one-semester course during the winter semester. One year later, the course was changed to a two-semester course to provide a greater structure for project development. Students also enroll in a one-credit course associated with the culminating implementation trip.

Students in the course come from chemical, civil and environmental, electrical and computer, and mechanical engineering programs in addition to technology programs such as industrial design and manufacturing engineering technology. The course is limited to 20 students that are divided into four teams composed of five students each. Since demand for the course is high, a course application and interview process has been implemented to select the students.

In the one-credit course during the fall semester, students receive instruction in product design with a specific emphasis on design for the developing world. The instruction includes a review of the engineering design and product development process, identification of methods for conceptual design and prototyping, and identification of technical and social constraints that

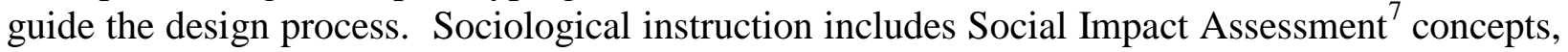
communication, interview guides, field observations, note taking, and coding of notes. Students also have an opportunity to practice concept generation and prototyping with a goal to narrow their project ideas to two or three possible designs before the winter semester.

During the winter semester, the two-hour course primarily involves prototyping and redesigns with a goal to have an implementable project by the end of the semester. Regular design reviews conducted by previous GEO students and faculty who have participated in the implementation trips provide continual feedback on project development. An important aspect of the project development is the near-weekly interactions the teams have with members from the developing communities. Typically, each team has a student representative that is fluent in Spanish who calls and/or uses email to interact with a designated community member. As communities in Peru have been a focus of project development since 2008, it is beneficial that many students in the GEO course speak Spanish fluently. At BYU, over $60 \%$ of students fluently speak a second language which provides a great opportunity for students to work on global projects.

A unique aspect of the course is the integration of the ASRM course during the fall semester. This course is taught at the same time as the GEO course. Sociology students register for the ASRM course and engineering and technology students register for the GEO course. Students from both courses meet together six times throughout the fall semester to receive instruction related to the sociological instruction previously noted. Students in the ASRM course are assigned to the four GEO project teams to interact during the joint classes and to work on homework assignments associated with the projects.

The two-week implementation trip occurs in late April following the winter semester. Students only participate one time in the course so continuity with the community is achieved by having the GEO instructor return each year, having one student participating in the trip serve as a TA for the GEO class the subsequent year, and providing reports and videos to the subsequent class. Implementation trips occurred in 2007 to Tonga, in 2008 to Peru and Ghana, and in 20092014 to Peru. Some examples of implemented projects include water purification, water storage, water delivery, water heating, solar cooking, windmills, and bio-filter toilets. Upon completion 
of the trip, student teams are required to write a detailed report and provide a video of the project design and implementation.

\section{LEARNING OUTCOMES AND ASSESSMENT}

There are five learning outcomes associated with the GEO course. Several aspects of the learning outcomes were assessed after the 2013 implementation trip and are shown below. Only twelve students participated in the assessment since it was voluntary.

The first outcome involves problem solving skills. Here, students gain experience in the design process that includes innovative problem solving skills applied to the design and implementation of global projects in developing regions of the world in the context of real needs, constraints, and opportunities. As shown in Table I, students feel strongly that they are always seeking new ideas and that they are building upon the strengths of each other's ideas. They are also committed to continually improving the project.

\section{TABLE I}

ASSESSMENT OF PROBLEM SOLVING SKILLS

\begin{tabular}{|l|c|c|c|c|c|}
\hline & $\begin{array}{c}\text { Strongly } \\
\text { Disagree }\end{array}$ & Disagree & Neutral & Agree & $\begin{array}{c}\text { Strongly } \\
\text { Agree }\end{array}$ \\
\hline $\begin{array}{l}\text { People on this team always look for new ways of } \\
\text { looking at problems }\end{array}$ & 0 & 0 & 0 & 5 & 7 \\
\hline In this team, we take time to develop new ideas & 0 & 0 & 2 & 8 & 2 \\
\hline $\begin{array}{l}\text { Team members built on each other's ideas in order to } \\
\text { achieve the best possible outcome }\end{array}$ & 0 & 0 & 0 & 6 & 6 \\
\hline $\begin{array}{l}\text { The team critically appraises potential weakness in } \\
\text { what it is doing in order to achieve the best possible } \\
\text { outcome }\end{array}$ & 0 & 1 & 2 & 5 & 4 \\
\hline $\begin{array}{l}\text { Team members are committed to ongoing } \\
\text { improvement. }\end{array}$ & 0 & 0 & 0 & 7 & 5 \\
\hline $\begin{array}{l}\text { I felt that I had enough time to assure that our } \\
\text { project was of high quality }\end{array}$ & 0 & 3 & 3 & 5 & 1 \\
\hline $\begin{array}{l}\text { I felt that I had time to assure the safety of our } \\
\text { project for users }\end{array}$ & 0 & 3 & 1 & 8 & 0 \\
\hline $\begin{array}{l}\text { I felt that it was safe to take a risk to try new things } \\
\text { in my group }\end{array}$ & 0 & 0 & 1 & 6 & 5 \\
\hline
\end{tabular}

As clearly shown with several of the responses, time is a constraint for ensuring the quality and safety of the project although safety is never compromised. Time constraints as a result of other commitments during school are a real challenge when integrating design courses for developing communities into the curriculum. In particular, the 3-credit GEO course results in a time constraint in the absence of students volunteering their personal time for the projects (which many students do because of their commitment to the project success). In 2015-16, there will be an additional two hours of in-class project time during the fall semester to foster more team opportunities. Out-of-class learning will also be increased during the winter semester. However, there will always be university constraints to time expectations of courses. Another notable aspect shown in Table I is that several students do not feel that they adequately critique some of the weaknesses during the design process in order to improve the project outcome. Perhaps the 
limited time for working on the projects leads to this feeling. Making weaknesses become strengths is beneficial during the design process and more assessment needs to occur to determine how to improve in this area.

The second outcome involves global appreciation where students have an opportunity to demonstrate an appreciation for global aspects of engineering, including social and technical constraints related to design and the importance of sustainability. According to Table II, about two-thirds of the students feel confident that they know enough about the culture and the design process to develop a project that would be useful for the developing community. Thus, there is still room for improvement in helping students know more about the culture and to have more experiences in product design. One challenge for this needed improvement is that many engineering students do not have much experience in open-ended product design. For some students, this was their first course in which they did a real engineering project that was implemented in a real-world context. It would be beneficial for students to have more of these open-ended experiences integrated throughout the curriculum, perhaps at a smaller scale. Another challenge is that students in the GEO class do not personally experience the culture prior to working on the project. Fortunately, many of the students have had a significant experience living abroad and many know the language but there is still great value in experiencing the culture where the project is being developed. Financial constraints have limited students from traveling both before the GEO class and during the implementation trip. One new aspect that has been recently implemented is that a significant amount of video is taken during each implementation trip. Following the trip, a student from each team will also provide an edited video showing an introduction of the project and the community members, a panorama of the project implementation area, various phases of the project implementation, and details of the final project. Thus, at the beginning of the semester, each team has many hours of video showing the community culture, implementation of previous projects, and information related to their particular project. These videos are also being used in the sociology segments of the class where students learn how to make observations and take field notes.

TABLE II

ASSESSMENT OF GLOBAL APPRECIATION

\begin{tabular}{|l|c|c|c|c|c|}
\hline & $\begin{array}{c}\text { Strongly } \\
\text { Disagree }\end{array}$ & Disagree & Neutral & Agree & $\begin{array}{c}\text { Strongly } \\
\text { Agree }\end{array}$ \\
\hline $\begin{array}{l}\text { I feel like our group knows enough about the culture } \\
\text { to ensure our GEO project will be useful for the } \\
\text { people of Peru }\end{array}$ & 0 & 0 & 3 & 6 & 3 \\
\hline $\begin{array}{l}\text { I feel like our group knows enough about the } \\
\text { product design to ensure our GEO project will be } \\
\text { useful the people of Peru. }\end{array}$ & 0 & 0 & 4 & 4 & 4 \\
\hline
\end{tabular}

The third outcome involves teamwork and leadership where students have the opportunity to demonstrate effective teamwork and leadership skills and show an appreciation for other disciplines both within and outside of engineering as they work together on interdisciplinary teams. From Table III, it is clear that team members are respectful of each other even though conflicts can arise regarding new ideas. Conflicts have generally been associated with the direction to pursue and not confrontational conflict. However, students are confident in bringing up issues that are tough to address. As noted, teams use their opposing views as strengths to better understand the issues rather than as a weakness that would result in the team not working 
well together. From an educational standpoint, students gain some new expertise related to their major. As for the interdisciplinary nature of the teams, which are usually composed of students from at least three disciplines, students feel that they learn new expertise that is unrelated to their major. This is important since a major emphasis of the course is to let students know that out in the real world, boundaries between engineering disciplines fade and all engineers at the simplest level are problem solvers, each contributing a unique viewpoint or technical background to solve the problem at hand.

TABLE III

ASSESSMENT OF TEAMWORK

\begin{tabular}{|l|c|c|c|c|c|}
\hline & $\begin{array}{c}\text { Strongly } \\
\text { Disagree }\end{array}$ & Disagree & Neutral & Agree & $\begin{array}{c}\text { Strongly } \\
\text { Agree }\end{array}$ \\
\hline $\begin{array}{l}\text { I felt I could bring up problems and tough issues to } \\
\text { my group members }\end{array}$ & 0 & 0 & 0 & 2 & 10 \\
\hline $\begin{array}{l}\text { I felt that my personal skills and talents were valued } \\
\text { by other members of my group }\end{array}$ & 0 & 0 & 0 & 5 & 7 \\
\hline $\begin{array}{l}\text { I have new expertise related to my major or program } \\
\text { emphasis from my participation in this project }\end{array}$ & 0 & 0 & 3 & 6 & 3 \\
\hline $\begin{array}{l}\text { I have new expertise unrelated to my major or } \\
\text { program emphasis from my participation in this } \\
\text { project }\end{array}$ & 0 & 0 & 2 & 5 & 5 \\
\hline $\begin{array}{l}\text { I felt that conflicts regarding ideas frequently arise in } \\
\text { my group }\end{array}$ & 3 & 3 & 2 & 3 & 1 \\
\hline $\begin{array}{l}\text { I feel that in my team we use our opposing views to } \\
\text { understand problems }\end{array}$ & 0 & 0 & 1 & 6 & 5 \\
\hline $\begin{array}{l}\text { People on the team cooperated in order to help } \\
\text { develop and apply new ideas }\end{array}$ & 0 & 0 & 2 & 8 & 2 \\
\hline
\end{tabular}

The fourth outcome involves communication where students demonstrate effective oral and written communication skills in the reporting of work, particularly to entities or individuals in countries in which projects are implemented. Table IV shows that from a communication standpoint, students are confident in the questions they ask. As part of the sociological training in the GEO course, students have to prepare an interview guide that categorizes questions they need to ask during the development process. The questions are updated on a monthly basis and the students have to report on their responses to the questions. The students do very well at this task and this is a likely reason for the confidence in the types of questions to ask. On the other hand, students don't always feel comfortable getting the feedback. Students generally feel confident about their Spanish skills since many have lived abroad for two years where they used the language daily. However, students have stated that because their Spanish was used in a different part of the world, cultural differences (speed, pronunciation, etc.) often provide some challenges and comfort issues when communicating with community members. This may be one reason for the lack of comfort in getting feedback (although this discomfort was with only a few of the students). A more obvious issue to address in the future is that students do not regularly critique their communication methods to improve. 
TABLE IV

ASSESSMENT OF COMMUNICATION

\begin{tabular}{|l|c|c|c|c|c|}
\hline & $\begin{array}{c}\text { Strongly } \\
\text { Disagree }\end{array}$ & Disagree & Neutral & Agree & $\begin{array}{c}\text { Strongly } \\
\text { Agree }\end{array}$ \\
\hline $\begin{array}{l}\text { I knew what to ask in order to get the feedback I } \\
\text { needed from potential users. }\end{array}$ & 0 & 0 & 0 & 9 & 3 \\
\hline $\begin{array}{l}\text { I felt comfortable getting the feedback I needed from } \\
\text { potential users }\end{array}$ & 0 & 1 & 1 & 7 & 3 \\
\hline $\begin{array}{l}\text { Our group was able to utilize Spanish speakers } \\
\text { effectively during the trip }\end{array}$ & 0 & 0 & 3 & 3 & 6 \\
\hline $\begin{array}{l}\text { We often discuss how well information in } \\
\text { communicated. }\end{array}$ & 0 & 4 & 4 & 4 & 0 \\
\hline
\end{tabular}

The fifth outcome involves social innovation where students gain experience in how to be involved in social innovation as they progress through their careers. Table $\mathrm{V}$ shows that the social innovation experience of designing and implementing projects for developing communities is very rewarding. Students become so involved in the projects that they lose track of time. This signifies that students participate in the experience because they enjoy it rather than because it is a requirement. As for areas of improvement, students feel that although the project objectives were worthwhile, the achievement of the objectives is a challenge. This likely goes back to the issue of available time. As students leave the university setting and potentially seek opportunities for working on projects in developing communities, time will always be an issue and one will need to decide how to balance their time with competing demands. To summarize the experience, one student on a previous trip stated, "Although BYU is an excellent place of learning, some things simply cannot be taught on campus. The recent GEO trip to Peru provided some opportunities, which I might otherwise never have experienced in any university setting. In Peru, we worked closely with the people. This intimate working relationship made me see and understand that the Peruvians think in very different ways than the people I am generally around. They have completely different perspectives. What I saw as dirt, they saw as building material. What I saw as insulation, they viewed as a child's play toy. It is good to realize that different people have different values. Finally, my eyes were opened to the possibilities of global markets. If these markets could be tapped, the revenue from each item might be a mere drop, but drops from all around the world form oceans."

Table V

ASSESSMENT OF SOCIAL INNOVATION EXPERIENCE

\begin{tabular}{|l|c|c|c|c|c|}
\hline & $\begin{array}{c}\text { Strongly } \\
\text { Disagree }\end{array}$ & Disagree & Neutral & Agree & $\begin{array}{c}\text { Strongly } \\
\text { Agree }\end{array}$ \\
\hline This experience was very rewarding. & 0 & 0 & 0 & 2 & 10 \\
\hline As I work on our project, I often lost track of time & 0 & 0 & 1 & 7 & 4 \\
\hline $\begin{array}{l}\text { Team members felt that the team's objectives were } \\
\text { worthwhile }\end{array}$ & 0 & 0 & 2 & 5 & 5 \\
\hline $\begin{array}{l}\text { Team members felt that the team's objectives were } \\
\text { achievable }\end{array}$ & 0 & 1 & 2 & 7 & 2 \\
\hline
\end{tabular}




\section{LESSONS LEARNED}

Since 2007, there have been many opportunities to learn and improve. Assessment has occurred throughout the years to provide guidance and direction for the course, community engagement, and the implementation trip. The information summarized below results primarily from the experiences in Peru where teams have worked with the communities of Salkantay (2008-10), Huatta (2011), Matinga (2012-13), Uros Islands (2009-14), and Porcón (2014). Teams are currently working with the communities of the Uros Islands and Porcón.

\section{Course:}

Initially, the course was a one-semester course offered during the winter semester. This was followed immediately by the implementation trip. The variable-credit course enabled students to adjust their commitment to the projects based on their availability. There were some difficulties with this approach. First, a one-semester course is difficult to provide sufficient time for students to develop projects, develop relationships with the community members, and to conceptualize and prototype the projects. Even with a two-semester course, time is still a challenge (See Table I). Second, variable-credit is not a good option since this leads to team members having variable commitments to the project. Experience in the course has shown that project development works more effectively when all students have the same expectations.

During the second year, the course was expanded to two semesters. The course was divided into two-credit hours during the fall semester and one-credit hour during the winter semester. The expansion to two semesters provided more development time but more time was needed during the second semester when prototyping was a major focus. During the second semester, students had to spend a significant amount of time on projects outside of typical class expectations in order for the projects to be completed. Although this extra commitment showed student passion for the projects, it was still desirable to develop a course structure that was more in alignment with project development. Currently, the course is a one-hour course in the fall semester and a two-hour course in the winter semester to help provide a better balance to project development. Future plans may involve expanding class time in the fall semester to facilitate earlier concept development so that prototyping can begin earlier.

As previously mentioned, integration of the ASRM course has provided engineering and technology students the opportunity to learn about social impact assessment and associated sociological aspects related to community engagement. Classroom activities involve teaching data collection techniques, identification of individual/household/community needs, identification of important features and conditions of the community context (social, economic, political, and cultural), learning participant observation techniques, taking field notes, conducting informal interviews with community members, and identifying central themes and patterns in transcribed notes that will facilitate project design. The integration of ASRM has been very beneficial and details of the impacts have been previously reported ${ }^{\mathrm{vi}}$.

Typically, many engineering programs train students with textbook instruction that involves problems with known solutions-often without much social context. Although technical constraints are often discussed in design textbooks ${ }^{8}$, information regarding social constraints is minimal. Thus, engineering students often have little or no training on design constraints associated with social context. Such constraints may include time, customs, traditions, trust, and resource availability ${ }^{\mathrm{v}}$. Although designs may be technically feasible, social constraints can often 
affect project sustainability. For example, a project was implemented in the village of Salkantay Peru involving the design of a water delivery system from a storage tank. The water delivery system was properly designed and worked very well although two of the lines leaving the storage tank were not at the same elevation. One line was a few inches higher than the other line. However, community members receiving water from the higher-elevation line were convinced that their water delivery would be slower than the water delivery going to community members with the lower elevated line. It was explained to the community members that the small elevation difference would not affect water delivery. However, upon return to the community at a later time, it was observed that the line with the lower elevation had been damaged to "help" more water go to the community with the higher elevated line. Although the design was technically correct, it was not socially correct. This has been a great learning experience for students since social constraints are not always obvious. For this case, the problem was easily fixed by reengineering the lines to be nearly the same elevation. This satisfied the community members.

As illustrated by this example, social constraints are not always obvious and it is difficult for students to recognize all possible social constraints. Currently, examples of past projects and projects reported in the literature ${ }^{9}$ have been used to help the students recognize a variety of social constraints. To help with this training, students are required to provide a social constraint document that contains the social constraint, the target value, the lower and upper limits, the current value, and the source used to identify the values. Students regularly engage with community members to identify potential social constraints and their target values.

\section{Community engagement:}

Community engagement is critical to the success of projects and it is fostered throughout the two semesters and during the implementation trip. During the early years of the course involving projects in Peru, the projects were coordinated with an NGO rather than with community members directly. The NGO worked with the community to identify projects of interest such that direct involvement of project selection and design by the GEO instructor and students was limited. The communities of Salkantay, Huatta, and Matinga primarily operated in this fashion. Interaction with the Uros Island community was initiated by the NGO but once contact was established, the GEO instructor directly coordinated projects with the Uros Island community. Interestingly, the projects coordinated through the NGO were less successful than the projects directly coordinated with the community. Currently, all projects are directly coordinated with community members and there are no NGO intermediaries.

One of the difficulties in working with an NGO is that there is not always clarity in the communication chain between the project teams and the community. For example, prior to the implementation trip, students provided a list of supplies to the NGO that were needed for the project. The NGO was responsible for coordinating the supply purchase with the community to make sure supplies were ready when the teams arrived. Unfortunately, supplies were rarely available upon arrival such that time was spent on the trip to secure the supplies. More problematic was that there were some cases where the community was not as engaged with the NGO as assumed by the GEO instructor. This disengagement led to some implementation trips where community engagement was sparse.

To alleviate the difficulties noted above, direct coordination between the GEO class and the communities was established and is the current protocol. In general, students now call on a nearweekly basis with their community partners to discuss project development. Fortunately, many 
students in the course are fluent in Spanish due to previous international experiences, some as long as two years while living in a Spanish-speaking foreign country. Currently, 11 of the 20 students in the course are fluent in Spanish. This has advantages for two reasons. First, students are more understanding of cultural differences and how to communicate with individuals in another culture. Second, direct contact between students and community members enables relationships to be fostered throughout the project development phase. This has been clearly evident upon arrival to the communities when community members embrace students they have interacted with during the previous two semesters. It has been clear from past experiences that removal of the NGO has fostered greater community/student relationships and greater project sustainability.

The Uros Islands is a community in which direct interaction between the community and students has been occurring since 2009. It is important to note that relationships take time to develop even when directly interacting with a community. During early experiences with the Uros Islands, community members readily agreed with many ideas although experience during the implementation trip demonstrated that this agreement was more polite than genuine. However, with extended experience in the Uros Islands, community feedback has become more genuine. For example, on a recent trip to the Uros Islands, a community member provided some information to the team that was not obvious to a general outsider. This information was extremely useful for understanding project development for future years. This experience emphasizes the building of trust which has been documented as an important component of working with communities. ${ }^{\text {ix }}$ Once trust is built, communities are more willing to share real needs and concerns. Importantly, relationships between the institution (such as BYU) and the community are just as critical for project development as relationships between student teams and the community since teams change each year. The importance of institutional continuity was recently evident when a new team recently assigned to a project for the Uros Islands made contact with a community member. Although the team was respectful of contact time on the phone and did not know the community member from past experience, the community member treated the new team members like "old-time" friends and spent a considerable amount of time just talking about the Uros Island community. It is unlikely that experiences like this would happen without regular and direct connectivity between the institution and the communities. It is important to recognize that working with an NGO can be beneficial but experience has shown that direct interaction of student teams with the community is essential.

As a result of the success in the Uros Islands through direct community interaction, a working relationship with the community of Porcón in northern Peru was recently established. This new relationship is important in light of social changes occurring in the Uros Islands where community members are moving off of the islands. With a declining population, it is important that there is a plan for future project development opportunities even though community engagement with the Uros Islands is still continuing. Porcón was selected as a result of our extensive Peruvian network that includes mayors, university presidents, medical professionals, engineers, and businessmen. In 2013, a pre-trip to Porcón occurred in which relationships were established and project opportunities were identified. The community of Porcón provides a unique situation in that the community has pulled themselves out of poverty through selfdeveloped initiatives associated with fish farms, lumber, cheese making, and other venues. However, there are still opportunities for project development since there are still design challenges, such as the need for hot water, and there are opportunities to improve some of their current processes (such as herbal tea collection and packaging that are not very efficient). 
Porcón has also brought additional student educational opportunities since, unlike previous experiences, the GEO students live and eat in the community. A beneficial sign of community engagement was Porcón's investment in providing housing and food for students during the recent implementation trip. To further establish community relationships, one student remained in Porcón during the entire summer and the GEO instructor returned with his family for two additional weeks.

\section{Implementation trip:}

The two-week implementation trip occurs within a few days following the winter semester. In general, a majority of the students participate in the trip since part of the application process for the GEO course involves assessment of student interest and commitment to the trip. During the winter semester prior to the trip, cultural and safety discussions occur to prepare the students for the trip. Students typically pay two-thirds of the trip cost with the balance covered by college subsidies. The trip is coordinated through the David M. Kennedy Center for International Studies at BYU.

The implementation involves three segments: implementation of projects in the Uros Islands (4-5 days), implementation of projects in Porcón (4-5 days), and a trip to Machu Picchu (2 days). Student teams involved with project implementation in one location still help with projects implemented in the other location. In addition to implementing the projects, students take notes and videos for project reports, assess projects from the previous year, and work with the community members on identifying projects for the subsequent year. During the trip, students are expected to maintain a journal that includes at least a) personal experiences, b) cultural experiences, c) observed social and design constraints related to the project, and d) data collection and results while on the trip. An important educational aspect of the implementation trip was noted from a recent pre- and post-trip survey conducted during the 2012-13 GEO class. In the pre-trip survey, $57 \%$ of the student respondents noted that technical specifications were the most discussed item with community members but only $33 \%$ of the respondents noted this as the most discussed item during the implementation trip. As students interacted with the community during the trip, there was a shift toward community issues and away from technical specifications as the top priority of project design. Furthermore, sustainability became a greater priority for the students. In general, by working in Peru, the students' priorities shifted from the technical specifications and towards sustainability, usability, and community benefits. The implementation trip is clearly an important part of the educational process for students.

\section{Case Study}

With the extensive experience in the Uros Islands, project success and sustainability has become more prevalent during the latter years of project implementation. Some of the success may be due to second and third generation project designs and/or the increased community trust that has been established. The following case study describes the development and implementation of a washing machine on the Uros Islands. Two models were developed: a hand-crank rotating washing machine implemented in 2012 and a simple rocking washing machine implemented in 2013.

Community members in the Uros Islands identified the interest for a washing machine during the 2011 implementation trip. Washing clothes on the island typically takes 3-6 hours each week 
and the women become very wet during the process. In addition, washing individual pieces of clothing in the very cold water results in sore hands. Following discussion with the community members, one team during the 2011-12 GEO course developed the hand-crank rotating washing machine shown in Figure 1. Briefly, the washing machine was made from a 35-gallon drum that was placed in a 55-gallon metal drum cut in half. The smaller barrel had an opening for adding clothes and perforated holes to induce washing. A bicycle pedal crank was attached to rotate the inner barrel. The outer barrel was filled with water and detergent and washing occurred while rotating the barrel. Once the washing was completed, clean water was placed in the outer barrel and the inner barrel was rotated to induce rinsing. The implementation cost was approximately $\$ 115$ USD. During the implementation process, students worked closely with community members. As a result of feedback from community members, the design was changed from an outer plastic drum supported by wood to an outer metal drum supported by metal legs. Initial feedback was positive although some women mentioned tiredness from turning the crank. Although the washing machine was well received compared to the traditional method of washing clothes, the constraint of cost made it difficult for widespread acceptance.

Based on feedback from the community, a second-generation design was developed during the 2012-13 GEO class. Again, students regularly interacted with community members throughout the design process. The simplified design, shown in Figure 2 was a 55-gallon horizontal barrel containing a corrugated inner sheet that was rocked back and forth on the ground using a pole attached to the side. At the request of the community members, a lid was placed on the barrel opening to minimize the loss of water. As for assessment, dirty clothing and a white cloth with dye were tested in the washing machine. After 10 minutes of agitating, all of the clothing samples were cleaned except for a very faint impression of the darkest dye. Community members performed visual and olfactory tests and determined that the clothes were clean enough to wear. The final cost of the washing machine was approximately \$50 USD.

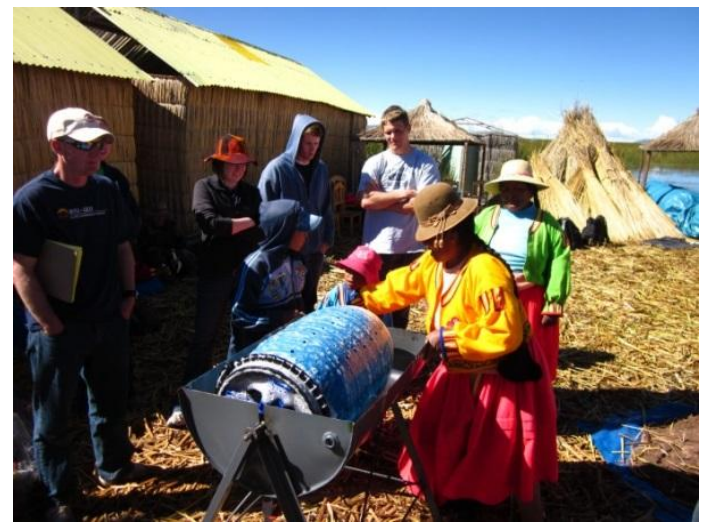

FIGURE 1

2012 Washing Machine on Uros Islands

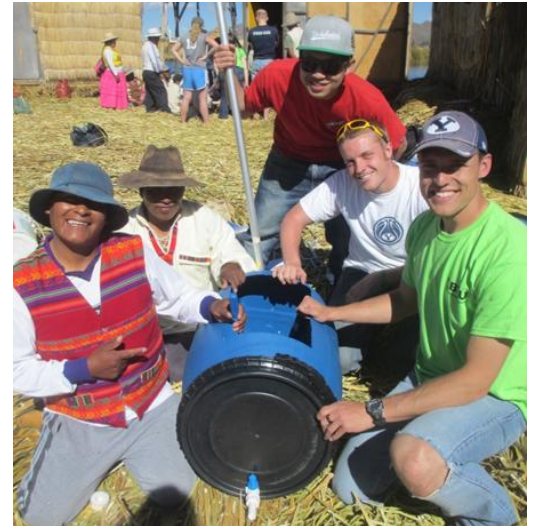

FIGURE 2

2013 Washing Machine on Uros Islands

During both implementation years, community members worked with the team in building several washing machines. Community members paid for all of the supplies. During a follow up visit in 2014, the GEO instructor visited a man who had one of the washing machines. He was very excited to report that he used the washing machine but he mentioned that he didn't use it for his own clothing. Instead, he washed his personal clothes by hand. He used the washing 
machine for washing bedding that was used for tourists. It was not initially clear as to why he still washed his clothes the traditional way until further probing provided understanding that there is a law that outlaws using the same washing container for tourist items and personal items. Further questioning revealed that the community member wanted another washing machine but he did not feel that he had the ability to create another unit-even though the design had been greatly simplified. Upon addressing the sustainability issue with community members on the washing machine and other implemented projects, it became clear that this community did not feel confident in replicating the projects. However, they were very willing to help with building projects, testing projects, providing feedback, and paying for the supplies.

\section{CONCLUSIONS}

In summary, there are several key aspects that are noteworthy for involving students in designing and implementing projects in developing communities.

1. Engineering students need to understand the social context to effectively incorporate social constraints in the design. Social constraints are not always obvious and teaching constraints by past examples is helpful.

2. Direct interaction of student teams with community members provides greater community engagement and trust than working through an NGO intermediary. Having students that fluently speak the language and have lived abroad provides a better communication avenue. It is important that there is regular correspondence throughout the design process.

3. Communication can sometimes be challenging even when there has been a strong sense of community engagement developed over the years. As for the washing machine, it took some probing to find out why the owner of the washing machine did not use the machine for his own clothing. Student teams often have to probe, with patience, many questions that are not always obvious before finding answers.

4. Multiple-generation projects tend to have better sustainability. Although the washing machine is only one example, projects involving pumps, water purification, and water heating have been the most successful and sustainable projects implemented in Peru as a result of developing second- and third-generation designs. The increased sustainability is likely a result of continual feedback from community members that trust the design process.

5. Involving the community in assessment is important since they feel ownership of the design process. Having community members feel part of the team, rather than being an observer, strengthens community engagement. Several projects implemented on the Uros Islands have incorporated design details suggested by the community members that have made the projects more sustainable.

6. A community ability to replicate projects is not always necessary for successful project implementation. For instance, the washing machines were regularly used even though 
they were not replicated and a water filtration system has been regularly maintained for the past three years although new water filtration systems have not been replicated.

7. Working in communities over long periods of time where relationships can be established, trust is developed, community commitment occurs (such as Porcón providing housing and food), and appreciation for each other occurs provides a viable working environment for designing and developing projects in developing communities.

8. Implementing a design course for developing communities within the curriculum is best established over two semesters. However, time constraints are still a challenge.

In general, students have great learning opportunities when participating in design projects for developing communities. However, there are still many opportunities to strengthen the educational experience.

\section{ACKNOWLEDGMENTS}

The 2012 washing machine was designed by Debbie Rich, Chelsea Kimble, Joseph Blanch, Greg Atkinson, Kevin Couch, Charles Wood, and Dan Talbert. The 2013 washing machine was designed by Jared Bruton, Zach Baird, Cuyler Frisby, and Jay Liu. Dr. Carol Ward is the instructor of the ASRM course.

\section{REFERENCES}

\footnotetext{
${ }^{1}$ Art Pine, "Strange Labfellows", ASEE Prism, March/April (2013).

${ }^{2}$ Allyson Frankman, Jacob Jones, W. Vincent Wilding, and Randy S. Lewis, "Training internationally responsible engineers", Proceedings of the 2007 ASEE Annual Meeting, Honolulu, HI (2007).

${ }^{3}$ Randy S. Lewis, and W. Vincent Wilding, "Student learning through Engineers Without Borders" AIChE National Meeting Abstracts, Philadelphia, PA, November (2008).

${ }^{4}$ Jared Geddes, W. Vincent Wilding, and Randy S. Lewis, "Sustainability and impact of global projects", Proceedings of the 2009 ASEE Annual Meeting, Austin, TX (2009).

${ }^{5}$ Amy Wood, Parry F. Garff, Carol J. Ward, Eric Dahlin, and Randy S. Lewis, "Social constraints: A critical component of global humanitarian-based projects", Proceedings of the 2013 ASEE Annual Meeting, Atlanta, GA. (2013).

${ }^{6}$ Parry F. Garff, Eric Dahlin, Carol J. Ward, and Randy S. Lewis, "Analysis of integrated engineering and social science approaches for projects in developing communities", International Journal for Service Learning in Engineering, Humanitarian Engineering and Social Entrepreneurship, Special Edition: 137150, (2013).

${ }^{7}$ Rabel Burdge, "A Community Guide to Social Impact Assessment (3rd Ed.)" (Middleton, WI): Social Ecology Press (2004).

${ }^{8}$ Mahmoud, M.S. in Decentralized Systems with Design Constraints (Springer, New York, NY, 2011).

${ }^{9}$ Juan Lucena, Jen Schneider, and Jon A. Leydens, Engineering and Sustainable Community Development (Morgan and Claypool, 2010).
} 